\title{
Nasal ventilation in COPD exacerbations: early and late results of a prospective, controlled study
}

\author{
G. Bardi, R. Pierotello, M. Desideri, L. Valdisserri, M. Bottai, A. Palla
}

Nasal ventilation in COPD exacerbations: early and late results of a prospective, controlled study. G. Bardi, R. Pierotello, M. Desideri, L. Valdisserri, M. Bottai, A. Palla. (C) ERS Journals Ltd 2000.

ABSTRACT: Noninvasive positive pressure mechanical ventilation (NIPPV) in exacerbated chronic obstructive pulmonary disease (COPD) has been investigated early and after 1 yr of follow-up.

To this end, 30 patients were enrolled in a prospective, controlled trial: 15 had early administration of NIPPV (Group A), 15 had medical therapy only (Group B); assignment was made on the basis of equipment availability only.

In-hospital mortality, need for endotracheal intubation and mean length of hospitalization were lower in Group A, though the difference was not statistically significant. Arterial oxygen tension in arterial blood $\left(\mathrm{Pa}_{\mathrm{a}}, \mathrm{O}_{2}\right)$, carbon dioxide tension in arterial blood $\left(\mathrm{Pa}_{\mathrm{a}} \mathrm{CO}_{2}\right)$ and $\mathrm{HCO}_{3}{ }^{-}$improved significantly in both groups from admission to discharge: $45.8 \pm 8.6$ versus $64.9 \pm 10.0 ; 59.4 \pm 11.8$ versus $48.6 \pm 7.3 ; 34.3 \pm 4.3$ versus $30.1 \pm 3.4$ in group $A ; 49.2 \pm 11.4$ versus $60.9 \pm 8.2 ; 52.6 \pm 15.9$ versus $44.4 \pm 8.7 ; 31.7 \pm 5.9$ versus $28.0 \pm 3.6$ in group $\mathrm{B}$, respectively, $\mathrm{p}<0.05$ for all comparisons; $\mathrm{pH}$, percentage forced expiratory volume in one second (FEV1) and tidal volume (VT) improved significantly in patients of group $A$ only: $7.36 \pm 0.04$ versus $7.41 \pm 0.02 ; 39.8 \pm 13.6$ versus $49.4 \pm 11.7 ; 0.71 \pm 0.3$ versus $0.84 \pm 0.4$, respectively, $p<0.05$. During follow-up, 3,6 , and 12 months survival rates were significantly higher in Group $A$ than in Group $B(p<0.02)$. Hospital new admissions over 1 yr were more frequent in Group $B(n=6$, incidence rate: $0.216 \%)$ than in Group $A(n=4$, incidence rate: $0.084 \%)$.

Therefore, noninvasive positive pressure mechanical ventilation may be added to "conventional" medical therapy in exacerbated chronic obstructive pulmonary disease.

Eur Respir J 2000; 15: 98-104.
Cardiopulmonary Dept, University of Pisa, and CNR Institute of Clinical Physiology, Pisa, Italy.

Correspondence: A. Palla Cardiopulmonary Dept University of Pisa Via Paradisa, 2 56124 Pisa Italy Fax: 39050580126

Keywords: Chronic obstructive pulmonary disease exacerbation chronic obstructive pulmonary disease prognosis

nasal ventilation

Received: December 91998

Accepted after revision August 161999

This work was supported in part by the Italian Ministry of the University and of Scientific and Technological Research.
Acute respiratory failure (ARF) is a common and frequently fatal complication in patients with chronic obstructive pulmonary disease (COPD) that requires hospital admission and often needs mechanical ventilation [1]. Indeed, conventional medical therapy may fail to manage such patients and failure may reasonably be predicted [2]; moreover, even when medical therapy seems to work, the patients' prognosis is poor [3].

Recently, a great deal of interest has been raised in the use of noninvasive positive pressure mechanical ventilation (NIPPV) [4, 5]. However, several controversial issues are present in this field. Firstly, indications for NIPPV still are ill defined, mostly in patients with mild and moderate acidosis who represent by far the majority of those admitted to a regular medical ward or to a Division of Respiratory Diseases. Indeed, at variance with the previously quoted authors, $[4,5]$, BARBÉ et al. [6] found that NIPPV administered for $6 \mathrm{~h}$ a day during the first 3 days of hospitalization does not facilitate recovery from ARF in such patients; likely, FogLio et al. [7] demonstrated that NIPPV for $4 \mathrm{~h}$ a day for five consecutive days a week for 3 weeks does not have a better result than standard therapy alone. Furthermore, the effect of late treatment with NIPPV after an acute exacerbation in terms of patients' survival, need for further hospital admissions or need for invasive mechanical ventilation is not fully known, though CoN-
FALONIERI et al. [8] demonstrated an improvement in the long-term outcome of a group of patients treated with NIPPV compared to a group of historically matched control patients treated conventionally. In spite of the design limitations of this study, the results appear to be of interest mostly in the light of the poor patients' outcome following hospitalization for exacerbation of COPD [9].

To investigate the role of NIPPV delivered in COPD patients with ARF of mild and moderate degree, hospitalized in a regular ward of the Division of Respiratory Disease, a prospective, controlled study was designed to compare the efficacy of nasal ventilation plus medical therapy versus medical therapy alone; results were evaluated both early during hospitalization and later after $1 \mathrm{yr}$ follow-up.

\section{Patients and methods}

Consecutive patients admitted to the Division of Respiratory Disease between October 1st, 1995 and December 31st, 1996 because of ARF of mild and moderate degree due to COPD exacerbation who had never been treated before with mechanical ventilation were enrolled onto the study. COPD was diagnosed on the basis of history, physical examination, standard chest radiography, spirometry 
and arterial blood gas values [10]. COPD exacerbation was characterized by increased dyspnoea, cough or sputum production. ARF was defined according with values of oxygen tension in arterial blood $\left(\mathrm{Pa}_{\mathrm{a}} \mathrm{O}_{2}\right) \leq 60 \mathrm{mmHg}$ while breathing room air, with or without carbon dioxide tension in arterial blood $\left(\mathrm{Pa}_{\mathrm{a}} \mathrm{CO}_{2}\right)>45 \mathrm{mmHg}$. Only patients with $\mathrm{pH}$ not lower than 7.30 were enrolled into the study in order to select those with mild and moderate ARF. Such a cut-off value of $\mathrm{pH}$ was chosen to avoid the enrolment of patients with severe ARF who should be treated in an intensive care setting $[10,11]$. Exclusion criteria were those reported by KRAMER et al. [12]. The Glasgow Coma Score (GCS) was employed to evaluate the rapid deterioration in neurological patients' status on admission [13]. Patients received either nasal mask NIPPV with a bilevel positive airway pressure ventilator $(\mathrm{BiPAP} \mathbb{R}$, Respironics Inc., Murraysville, PA, USA) and "conventional" medical therapy (Group A) or "conventional" medical therapy alone (Group B). Assignment of patients to one group was made only on the basis of ready availability of the necessary instrument for NIPPV and/or nurses experienced in the management of such a technique; at the moment of the study, only two instruments were available and two nurses (over a total of 12 working in the ward) were experienced in managing ventilatory technique. Such an availability was independent of the patient's clinical conditions. By the term "conventional" medical therapy the authors mean the standard medical therapy for COPD exacerbation that makes use of steroids, $\beta_{2}$-agonists, theophylline, antibiotics and diuretics; no respiratory stimulants were used. Oxygen supplemenation was administered at low doses with the aim of maintaining oxyhaemoglobin $\left(\mathrm{HbO}_{2}\right)$ over $90 \%$. Medical therapy was then tapered off individually to the maintenance therapy in both groups.

Physical examination, chest radiography, spirometry and arterial blood gas values were scheduled both on admission and on discharge from the hospital. In particular, spirometry was performed whenever possible by a computerized pneumotacograph (model 21X073A; Hewlett Packard, Coppertino, CA, USA) in the pulmonary function laboratory where the patient was brought within $24 \mathrm{~h}$ after admission; forced vital capacity (FVC) could be obtained either by the previous instrument or by a portable pneumotaco-

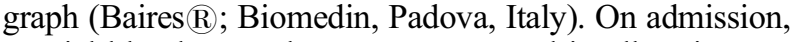
arterial blood gas values were measured in all patients at bedside, both while breathing room air and then with an oxygen supplementation to maintain $\mathrm{HbO}_{2}$ values of $\sim 90 \%$; subsequently, it was monitored under oxygen supplementation. On discharge arterial blood gas values were measured while breathing room air.

In case of worsening of respiratory conditions, endotracheal (ET) intubation was possible at any time and criteria for ET intubation and invasive mechanical ventilation were predefined. More specifically, ET intubation was performed if any of the following criteria were fulfilled: cardiac or respiratory arrest, psychomotor agitation due to hypercapnia requiring sedation, severe obtundation or loss of consciousness. Informed consent was obtained from each patient.

\section{Noninvasive mechanical ventilation}

A pressure support ventilation (PSV) and external positive end-expiratory pressure (PEEP) was provided by a compact bilevel positive airway pressure ventilator (BiPAP $(\mathrm{R})$
Respironics Inc.) in spontaneous mode. The device has a very sensitive flow trigger and it is able to perceive and compensate for air leaks. Inspiratory positive airway pressure (IPAP) and expiratory positive airway pressure (EPAP) values were set independently; IPAP was increased progressively until obtaining the highest level of IPAP tolerated by the patients; EPAP was set to $2-4 \mathrm{cmH}_{2} \mathrm{O}$. A nasal mask (Contour $\mathbb{R}$; Respironics Inc.) was used in all instances after having chosen the patient's proper size; the standard Whisper-Swivel@ (Respironics Inc.) exhalation device was employed, since it was the only device available at the moment of the study. Ventilatory support was delivered for at least $20 \mathrm{~h}$ (all day, except for pauses due to meals and personal care) on the first day of treatment; thereafter, the ventilation time was progressively reduced to a standard schedule of $3 \mathrm{~h}$ in the morning, 3 in the afternoon and 7 during the night. NIPPV was stopped when patients showed stable clinical conditions, i.e. disappearance or reduction of dyspnoea by at least one degree of the dyspnoea classification scale as compared to the value obtained at enrolment, and when values of $\mathrm{HbO}_{2}$ reached $>90 \%$ with an oxygen supplementation flow of $\leq 1 \mathrm{~L} \cdot \mathrm{min}^{-1}$ in at least two consecutive arterial drawings. To evaluate the degree of dyspnoea a slightly modified version of the British Medical Research Council questionnaire was employed [14]. Four degrees of dyspnoea were considered: 1) patient had shortness of breath when hurrying on level ground, walking up a slight hill or a flight of stairs at a walking pace; 2) the patient had shortness of breath when walking with other people of their own age on level ground; 3) they had to stop for breath when walking at their own pace on ground level; 4) they showed shortness of breath when dressing or undressing themselves.

\section{Setting of the study and nursing care}

Patients were admitted and treated in a regular ward of the Division of Respiratory Disease which had 17 beds, where an intensive care unit (ICU), though not present in the same building, was promptly available. NIPPV was applied either by pneumologists or by nurses; a pneumologist decided the initial setting of IPAP and EPAP. In order to keep the mouth closed, the caregiver taught patients and put strappings around their head when necessary. During the earliest phases of ventilation (30-60 $\mathrm{min}$ ), a pneumologist was continuously present at the patient's bedside; later on, the patient was monitored by the experienced nurse while the physician was on call. The nurse checked for the efficiency of instrumentation, for patient's tolerance of mask ventilation and for possible air leaks of the system. A patient's relative was allowed to assist the patient, who needs psychological support mostly in the first few hours after hospital admission.

\section{Data recording}

Mortality rates, need for ET intubation, mean length of hospitalization, spirometry, arterial blood gas values, respiratory rate and heart rate on discharge from hospital were investigated. Success rate was also considered, and was defined as avoidance of both death and ET intubation. Discharge from hospital was decided by pneumologists on 
the basis of satisfactory clinical conditions and arterial blood gas values. Patients were then followed for $1 \mathrm{yr}$ as out-patients by the physicians of the pneumological unit which guaranteed an even medical treatment in patients of both groups. Out-patients were scheduled for a visit 3, 6 and 12 months after discharge; on each follow-up visit patients were submitted to accurate clinical evaluation; chest radiography and noninvasive measurement of arterial saturation; if the latter was $<90 \%$, an arterial blood sample was collected to measure $\mathrm{pH}, \mathrm{Pa}, \mathrm{O}_{2}$ and $\mathrm{Pa}_{2}, \mathrm{CO}_{2}$. During the entire follow-up, the patients' General Practitioner and the patients themselves were instructed to call pneumologists from the ward whenever respiratory symptoms or signs had worsened or new symptoms had occurred. Simple exacerbations without ARF were treated with home medical therapy only, while respiratory exacerbations with ARF were taken into consideration for new hospital admissions. During such admissions the regimen of medical therapy did not vary between the two groups of patients and the use of NIPPV was possible in both groups according to the baseline criteria previously described. Survival rates and number of further hospital admissions were investigated 3, 6 and 12 months after discharge.

\section{Statistical analysis}

The analysis was performed both by including (intention-to-treat approach) and by excluding the two drop-out patients who did not tolerate the ventilatory support. All tables show the results obtained by including the two dropout patients, and differences are reported in the text only. Data are presented as mean \pm SD. Nonparametric tests were used to compare the two independent treatment groups (Wilcoxon rank-sum test) and the paired observations on admission and discharge in the same patient (Wilcoxon rank-signed test). A p-value $<0.05$ was considered to be significant. In each treatment group, the incidence rate of new admissions was computed as the ratio between total number of new admissions and cumulative number of days that patients survived over the entire follow-up. They were compared by performing an exact test using Binomial probabilities (given the relatively small sample size, exact test probabilities might be preferable to relying on asymptotic approximations). The Kaplan-Meier method was used to describe survival. Differences in survival between groups were assessed using the long-rank test for equality of survivor functions [16].

\section{Results}

Thirty patients, 15 included in Group A (13 males, mean age $68 \pm 8 \mathrm{yrs}$ ) and 15 in Group B (14 males, mean age $70 \pm 8 \mathrm{yrs}$ ), were studied. Individual status of all patients is reported in table 1 . Table 2 shows the comparison of baseline data between the two groups expressed as mean \pm SD. Patients of Group A and those of Group B matched well with the exception of $\mathrm{Pa}_{2} \mathrm{CO}_{2}$ and $\mathrm{HCO}_{3}{ }^{-}$(table 2).

Mean duration of total ventilatory assistance was $9 \pm 3$ days (range 5-14), mean duration of daily ventilatory assistance was $12 \pm 3 \mathrm{~h}$ (range 8-16). Mean IPAP and EPAP were $13 \pm 2 \mathrm{cmH}_{2} \mathrm{O}$ (minimum 12, maximum 16) and $3 \pm 1$ $\mathrm{cmH}_{2} \mathrm{O}$ (minimum 2, maximum 4).
Only minor side-effects in patients treated with NIPPV were observed (two patients complained of conjunctivitis and one patient of nasal ulceration, that improved with medical therapy).

\section{Early outcomes}

In-hospital outcome and patients' data on discharge are reported in table 3 . Two patients $(13.3 \%)$ failed to tolerate NIPPV but were analysed in the group $\mathrm{A}$ as in an intention-to-treat analysis (drop-out) (table 3). Mortality rate (no patients died in group A and one died in group B), need for ET intubation and mechanical ventilation (one patient in Group A and two patients in Group B) and mean length of hospitalization $(18 \pm 5$ (mean \pm SD) days in Group A and $23 \pm 13$ days in Group B) did not show statistical difference between the two groups although a trend in favour of patients treated with NIPPV was clearly appreciable (table 3). Success rate during hospitalization was $93.3 \%$ (92.3\% by excluding the two drop-out patients) in Group A and 80\% in Group B (difference was not significant); the trend was once again in favour of Group A patients (table 3).

Three patients required ET intubation and one died during the inhospital course. Late follow-up was analysed from the remaining 26 patients. In patients who completed inhospital follow-up (14 in Group A and 12 in Group B), no statistically significant differences were found between the two groups on discharge as regards to hospital outcome, level of dyspnoea and functional data (table 3 ). However, $\mathrm{pH}$, forced expiratory volume in one second $(\mathrm{FEV} 1) \%$ and tidal volume $(V \mathrm{~T})$ improved in a statistically significant way between admission and discharge in patients of group A only ( $\mathrm{p}<0.05$; table 4$)$.

\section{Late follow-up}

As previously reported (table 3 ), four patients were lost to follow-up before hospital discharge; last available arterial blood gas values, together with the causes of exclusion, are reported in table 5.

Patients of Group A had a total of four further hospitalzations after discharge, patients of Group B had six. One of these patients was admitted in a pulmonary unit different from the authors' but the patient's clinical and gasometric data were easily obtained. NIPPV was applied in two instances $(50 \%)$ among patients of Group A and in one (16.6\%) in patients of Group $\mathrm{B}$, once again according to the availability of the necessary instrument and/or experienced nurses.

A significant increase in survival rates was present in patients of Group A with respect to patients of Group B (fig. 1). In the former group no patient had died 3 months after discharge, one patient $(7.1 \% ; 8.3 \%$ by excluding the two drop-out patients) had died 6 months after discharge, two patients $(14.3 \% ; 16.7 \%$ by excluding the two dropout patients) had died 12 months after discharge. In the latter group, three patients $(25.0 \%)$ had died 3 months, five patients $(41.7 \%) 6$ months, and seven patients (58.3\%) 12 months after discharge. Difference between groups was highly significant $(p<0.02$; fig. $1 ; p<0.03$ by excluding the two drop-out patients). The main cause of death in both groups was ARF due to exacerbations of 
Table 1. - Patients' data on admission and early outcome

\begin{tabular}{|c|c|c|c|c|c|c|c|c|c|c|c|c|c|c|}
\hline $\begin{array}{l}\text { Patient } \\
\text { No. }\end{array}$ & Sex & $\begin{array}{l}\text { Age } \\
\text { yrs }\end{array}$ & $\begin{array}{l}{\mathrm{Pa}, \mathrm{O}_{2}} \\
\mathrm{mmHg}\end{array}$ & $\begin{array}{l}\mathrm{Pa}_{\mathrm{a}, \mathrm{CO}_{2}} \\
\mathrm{mmHg}\end{array}$ & $\mathrm{pH}^{*}$ & $\begin{array}{c}\mathrm{HCO}_{3} \cdot * \\
{ }^{\mathrm{mmmol} \cdot \mathrm{L}^{-1}}\end{array}$ & $\begin{array}{c}\text { Dyspnoea } \\
\text { level }\end{array}$ & $\begin{array}{c}\mathrm{RR} \\
\mathrm{br} \cdot \mathrm{min}^{-1}\end{array}$ & $\begin{array}{c}\mathrm{HR} \\
\mathrm{b} \cdot \mathrm{min}^{-1}\end{array}$ & GCS & $\begin{array}{l}\text { FEV1 } \\
\% \text { pred }\end{array}$ & $\begin{array}{l}V \mathrm{~T} \\
\mathrm{~L}\end{array}$ & $\begin{array}{l}\text { FRC } \\
\% \text { pred }\end{array}$ & $\begin{array}{c}\text { Early } \\
\text { outcome }\end{array}$ \\
\hline \multicolumn{15}{|c|}{ Group A } \\
\hline 1 & M & 57 & 35 & 68.9 & 7.32 & 35.2 & III & 31 & 120 & 13 & 53.9 & 0.60 & 93.1 & Discharge \\
\hline 2 & $\mathrm{M}$ & 63 & 60 & 65.8 & 7.32 & 34.7 & III & 32 & 80 & 13 & 30.2 & 0.63 & 145.6 & Discharge \\
\hline 3 & $\mathrm{M}$ & 50 & 50 & 63.5 & 7.35 & 35.6 & III & 36 & 100 & 14 & 19.0 & - & - & Discharge \\
\hline 4 & $\mathrm{~F}$ & 70 & 43 & 51.0 & 7.41 & 33.0 & IV & 34 & 74 & 15 & 31.3 & 0.47 & 79.2 & Discharge \\
\hline 5 & $\mathrm{M}$ & 57 & 50 & 32.5 & 7.45 & 22.6 & III & 34 & 92 & 15 & 65.5 & 1.30 & 117.9 & Discharge \\
\hline 6 & M & 75 & 46 & 66.6 & 7.35 & 37.6 & III & 32 & 85 & 14 & - & - & - & Discharge \\
\hline 7 & $\mathrm{M}$ & 66 & 57 & 55.4 & 7.30 & 33.9 & II & 38 & 80 & 14 & 46.5 & 0.60 & 90.7 & Drop out \\
\hline 8 & M & 76 & 43 & 52.7 & 7.35 & 29.6 & IV & 37 & 96 & 15 & 38.0 & 0.88 & 212.2 & Discharge \\
\hline 9 & $\mathrm{M}$ & 66 & 47 & 53.5 & 7.42 & 35.6 & III & 29 & 128 & 15 & 44.3 & 0.60 & 142.7 & Discharge \\
\hline 10 & $\mathrm{M}$ & 76 & 46 & 61.7 & 7.34 & 33.9 & III & 20 & 76 & 14 & 32.3 & 0.81 & 178.6 & ET intub. \\
\hline 11 & $\mathrm{M}$ & 67 & 38 & 65.8 & 7.37 & 38.0 & III & 36 & 85 & 13 & 28.8 & 0.49 & 135.6 & Discharge \\
\hline 12 & $\mathrm{~F}$ & 81 & 40 & 63.6 & 7.35 & 35.5 & II & 32 & 78 & 13 & - & - & - & Drop out \\
\hline 13 & $\mathrm{M}$ & 73 & 34 & 84.1 & 7.30 & 41.5 & IV & 40 & 88 & 13 & - & - & - & Discharge \\
\hline 14 & $\mathrm{M}$ & 67 & 59 & 54.9 & 7.39 & 33.1 & III & 28 & 92 & 15 & 40.9 & 0.85 & 231.8 & Discharge \\
\hline 15 & M & 67 & 39 & 53.8 & 7.40 & 33.7 & II & 41 & 64 & 15 & 39.2 & - & - & Discharge \\
\hline \multicolumn{15}{|c|}{ Group B } \\
\hline 16 & $\mathrm{M}$ & 63 & 57 & 45.0 & 7.30 & 28.6 & III & 27 & 90 & 15 & 32.7 & - & - & ET intub. \\
\hline 17 & $\mathrm{~F}$ & 83 & 53 & 56.0 & 7.38 & 33.6 & IV & 32 & 86 & 14 & 36.7 & - & - & Death \\
\hline 18 & $\mathrm{M}$ & 74 & 55 & 48.0 & 7.41 & 26.8 & IV & 30 & 100 & 15 & 24.8 & 0.89 & 145.5 & Discharge \\
\hline 19 & M & 65 & 55 & 50.2 & 7.39 & 29.5 & III & 20 & 80 & 15 & - & - & - & Discharge \\
\hline 20 & M & 72 & 52 & 47.0 & 7.38 & 25.9 & III & 35 & 60 & 15 & 34.9 & - & - & Discharge \\
\hline 21 & $\mathrm{M}$ & 63 & 51 & 60.4 & 7.34 & 32.2 & III & 19 & 106 & 13 & 18.1 & 0.77 & 233.3 & Discharge \\
\hline 22 & M & 67 & 52 & 40.4 & 7.41 & 28.8 & III & 34 & 72 & 15 & 55.7 & 0.80 & 109.0 & Discharge \\
\hline 23 & $\mathrm{M}$ & 75 & 54 & 42.5 & 7.44 & 29.2 & III & 28 & 84 & 15 & 38.2 & 1.01 & 162.8 & Discharge \\
\hline 24 & M & 58 & 52 & 51.0 & 7.40 & 30.9 & III & 36 & 54 & 15 & 40.5 & - & - & ET intub. \\
\hline 25 & $\mathrm{M}$ & 76 & 46 & 69.6 & 7.46 & 50.9 & IV & 38 & 120 & 14 & 24.4 & 0.65 & 132.3 & Discharge \\
\hline 26 & $\mathrm{M}$ & 68 & 44 & 50.1 & 7.42 & 31.8 & III & 34 & 69 & 15 & 24.9 & 0.72 & 167.0 & Discharge \\
\hline 27 & $\mathrm{M}$ & 79 & 52 & 42.0 & 7.42 & 26.2 & III & 31 & 86 & 15 & 56.9 & 0.79 & 83.3 & Discharge \\
\hline 28 & $\mathrm{M}$ & 67 & 44 & 59.2 & 7.36 & 32.9 & III & 37 & 94 & 14 & 28.7 & - & - & Discharge \\
\hline 29 & M & 64 & 38 & 62.8 & 7.32 & 32.7 & IV & 34 & 108 & 13 & - & - & - & Discharge \\
\hline 30 & $\mathrm{M}$ & 82 & 48 & 58.8 & 7.37 & 33.9 & II & 18 & 60 & 14 & - & - & - & Discharge \\
\hline
\end{tabular}

Group A received noninvasive positive pressure mechanical ventilation plus conventional medical therapy; group B received conventional medical therapy alone. M: male; F: female; $P \mathrm{a}, \mathrm{O}_{2}$ : arterial oxygen tension; $\mathrm{Pa}_{\mathrm{a}} \mathrm{CO}_{2}$ : arterial carbon dioxide tension; RR: respiratory rate; br: breaths; HB: heart rate; b: beats; GCS: Glasgow Coma Score; FEV1: forced expiratory volume in one second; VT: tidal volume; FRC: functional residual capacity; ET intub.: endotracheal intubation. *: arterial blood gas samples were obtained while patients were breathing room air. Static volumes were not available in 13 patients; forced vital capacity was not available in 6 patients.

COPD; no pneumonia was observed in these patients (table 6).

The total number of further hospital admissions was four (incidence rate $0.084 \%$ ) in Group A and six (incidence rate $0.216 \%$ ) in Group B. The former group, who lived longer, provided a cumulative survival of 4,774 person-days whereas the latter yielded 2,777 person-days. Exact test for the difference between the incidence rates was not significant (table 7). When data were analysed by excluding the two drop out patients from group A similar results were obtained (four events, 4,044 person-days, incidence rate $0.099 \%)$.

\section{Discussion}

The most important result of this study is that patients treated with positive pressure NIPPV through a nasal mask had a better survival rate and a lower incidence of hospital new admissions during the year following the discharge from the hospital in comparison to patients treated conventionally. Although other papers have reported on the late outcome of patients treated with NIPPV [17-19], only one other study has been published on the late outcome after an acute episode of respiratory failure in patients ventilated with a nasal mask [8]; however, such a study used
Table 2. - Comparison of patients' data between the two groups on admission

\begin{tabular}{|c|c|c|c|}
\hline $\begin{array}{l}\text { Baseline } \\
\text { parameters }\end{array}$ & $\begin{array}{c}\text { Group A } \\
\text { Added Bi-PAP }\end{array}$ & $\begin{array}{l}\text { Group B } \\
\text { Control }\end{array}$ & p-value \\
\hline Male $n$ & 13 & 14 & \\
\hline Female $n$ & 2 & 1 & NS \\
\hline Age yrs & $68 \pm 8$ & $70 \pm 8$ & NS \\
\hline Dyspnoea II level & 3 & 1 & \\
\hline Dyspnoea III level & 9 & 10 & NS \\
\hline Dyspnoea IV level & 3 & 4 & \\
\hline$P \mathrm{a}, \mathrm{O}_{2} \mathrm{mmHg}$ & $45.8 \pm 8.2$ & $50.9 \pm 8.6$ & NS \\
\hline $\mathrm{Pa}, \mathrm{CO}_{2} \mathrm{mmHg}$ & $59.58 \pm 11.4$ & $52.20 \pm 8.6$ & $\mathrm{p}<0.05$ \\
\hline $\mathrm{pH}$ & $7.36 \pm 0.04$ & $7.39 \pm 0.01$ & NS \\
\hline $\mathrm{HCO}_{3}{ }^{-} \mathrm{mmol} \cdot \mathrm{L}^{-1}$ & $34.2 \pm 4.2$ & $31.6 \pm 5.9$ & $\mathrm{p}<0.01$ \\
\hline $\mathrm{RR}$ br $\cdot \mathrm{min}^{-1}$ & $33.3 \pm 5.3$ & $30.2 \pm 6.6$ & NS \\
\hline HR $b \cdot \min ^{-1}$ & $89.2 \pm 16.9$ & $84.6 \pm 19.2$ & NS \\
\hline GCS & $14.1 \pm 0.9$ & $14.5 \pm 0.7$ & NS \\
\hline FEV1 \% & $39.2 \pm 12.4$ & $34.7 \pm 15.9$ & NS \\
\hline$V \mathrm{~T} \mathrm{~L}$ & $0.7 \pm 0.3$ & $0.8 \pm 1.1$ & NS \\
\hline FRC \% & $142.7 \pm 54.7$ & $147.6 \pm 48.0$ & NS \\
\hline
\end{tabular}

Data are shown as mean \pm SD. p-values are from Wilcoxon ranksum test. Bi-PAP: bilevel positive airway pressure; NS: not significant. *: arterial blood gas samples were obtained while patients were breathing room air. For further abbreviations, see legend to table 1 . 
Table 3. - In-hospital outcome and comparison of patients data between the two groups on discharge

\begin{tabular}{|c|c|c|c|}
\hline & $\begin{array}{c}\text { Group A } \\
\text { Added Bi-PAP }\end{array}$ & $\begin{array}{l}\text { Group B } \\
\text { Control }\end{array}$ & p-value \\
\hline \multicolumn{4}{|l|}{ Inhospital outcome } \\
\hline Drop out $\mathrm{n}$ & $2(13.3)$ & $0(0)$ & NS \\
\hline Death $\mathrm{n}$ & $0(0)$ & $1(6.7)$ & NS \\
\hline ET intubation $n$ & $1(6.7)$ & $2(13.3)$ & NS \\
\hline Length of stay days & $18 \pm 5$ & $23 \pm 13$ & NS \\
\hline Success rate \% & 93.3 & 80.0 & NS \\
\hline \multicolumn{4}{|l|}{ Patients' data } \\
\hline Dyspnoea II level & 9 & 5 & \\
\hline Dyspnoea III level & 5 & 7 & NS \\
\hline Dyspnoea IV level & 0 & 0 & \\
\hline $\mathrm{Pa}, \mathrm{O}_{2} \mathrm{mmHg}$ & $64.9 \pm 10.0$ & $60.9 \pm 8.2$ & NS \\
\hline 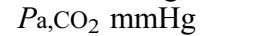 & $48.6 \pm 7.3$ & $44.4 \pm 8.7$ & NS \\
\hline $\mathrm{pH}$ & $7.41 \pm 0.02$ & $7.41 \pm 0.04$ & NS \\
\hline $\mathrm{HCO}_{3}^{-} \mathrm{mmol} \cdot \mathrm{L}^{-1}$ & $30.1 \pm 3.4$ & $28.0 \pm 3.6$ & NS \\
\hline $\mathrm{RR}$ br $\cdot \mathrm{min}^{-1}$ & $25.7 \pm 3.7$ & $23.2 \pm 4.8$ & NS \\
\hline HR b. $\min ^{-1}$ & $87.4 \pm 11.6$ & $79.5 \pm 12.4$ & NS \\
\hline FEV1 \% & $49.4 \pm 11.7$ & $40.5 \pm 18.9$ & NS \\
\hline$V \mathrm{~T} \mathrm{~L}$ & $0.84 \pm 0.4$ & $0.90 \pm 0.4$ & NS \\
\hline FRC \% & $138.3 \pm 32.3$ & $140.4 \pm 52.9$ & NS \\
\hline
\end{tabular}

Data are presented as absolute number with percentage in parentheses, and as mean \pm SD. The $p$-values are from the Wilcoxon rank-sum test. Bi-PAP: bilevel positive airway pressure; Drop out: patients who did not tolerate nasal mask ventilation; ET: endotracheal; Ns: nonsignificant. *: arterial blood gas samples were obtained while patients were breathing room air. For further abbreviations, see legend to table 1 .

historically matched control patients and, therefore, needs to be confirmed in a randomized trial or in a prospective controlled study. The current authors chose the second option since they were limited in the patients' enrollment by the availability of ventilatory devices and/or that of nurses experienced in managing the instrumentation. The authors are aware that the lack of a true, predefined randomization design may weaken the results of the study. However, all patients were consecutively assigned to the treatment group and the criteria for patients' intubation and for hospital discharge were predefined and identical in both groups.

An issue of great importance is that this study only enrolled patients with COPD exacerbations complicated by ARF of mild and moderate degree. Indeed, such patients represent the large majority of those admitted with ARF in

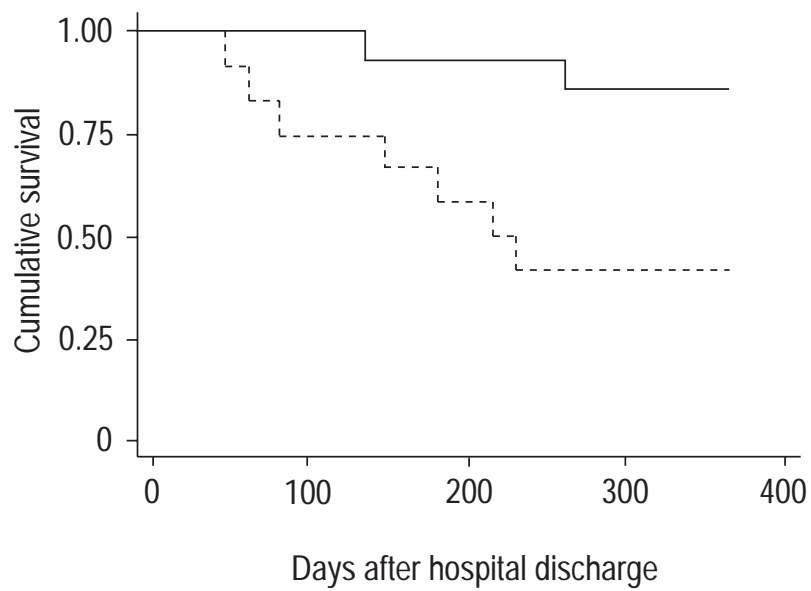

Fig. 1. - Kaplan-Meier survivor functions by treatment group $(\mathrm{p}<0.02$ by log-rank test). ——: group A patients; - - - group B patients.

a regular medical ward or in a Division of Respiratory Diseases not equipped with an ICU; therefore, improving their late outcome might decrease mortality for respiratory insufficiency and reduce the financial costs of repeated hospitalization. Patients with mild and moderate ARF are usually deemed to be at lower risk and, accordingly, are treated with medical therapy alone. Such physician behaviour has been reinforced by the recent demonstration by BARBE et al. [6] that NIPPV does not improve early mortality and need for ET intubation in such patients. However, BARBÈ et al. [6] did not follow their patients after hospital discharge, a period during which the current authors could demonstrate a better survival rate and a lower incidence of new hospital admissions. Moreover, CONNORS et al. [9] demonstrated that the outcome of patients following exacerbation of COPD is generally poor and ANTHONISEN [3] showed that, even when medical therapy seems to work, the patients prognosis is unsatisfying. A potential argument could be the choice of cut-off value of a $\mathrm{pH}>7.30$ to define the degree of ARF. Such a value was chosen according to MEDURI et al. [11] who demonstrated that patients with a $\mathrm{pH}<7.30$ should be treated in an intensive setting, a finding which, subsequently, allowed the American Thoracic Society to include, in their guidelines for patients admission to an ICU, the deterioration of respiratory acidosis $(\mathrm{pH}<7.30)[10]$.

The reasons why patients with ARF of a mild to moderate degree due to COPD exacerbations have such an improved late prognosis when ventilated with a nasal mask

Table 4. - Comparison of lung function parameters between the two groups on admission and discharge

\begin{tabular}{|c|c|c|c|c|c|c|}
\hline & \multicolumn{2}{|c|}{ Group A } & \multirow[b]{2}{*}{ p-value } & \multicolumn{2}{|c|}{ Group B } & \multirow[b]{2}{*}{ p-value } \\
\hline & Admission & Discharge & & Admission & Discharge & \\
\hline${\mathrm{Pa}, \mathrm{O}_{2}}^{*} \mathrm{mmHg}$ & $45.8 \pm 8.6$ & $64.9 \pm 10.0$ & $<0.01$ & $49.2 \pm 11.4$ & $60.9 \pm 8.2$ & $<0.01$ \\
\hline $\mathrm{Pa}_{2} \mathrm{CO}_{2} * \mathrm{mmHg}$ & $59.4 \pm 11.8$ & $48.6 \pm 7.3$ & $<0.01$ & $52.6 \pm 15.9$ & $44.4 \pm 8.7$ & $<0.05$ \\
\hline $\mathrm{pH}^{*}$ & $7.36 \pm 0.04$ & $7.41 \pm 0.02$ & $<0.01$ & $7.39 \pm 0.01$ & $7.41 \pm 0.04$ & NS \\
\hline $\mathrm{HCO}_{3}{ }^{-*} \mathrm{mmol} \cdot \mathrm{L}^{-1}$ & $34.3 \pm 4.3$ & $30.1 \pm 3.4$ & $<0.01$ & $31.7 \pm 5.9$ & $28.0 \pm 3.6$ & $<0.05$ \\
\hline FVC \% pred & $60.6 \pm 13.6$ & $70.9 \pm 18.1$ & NS & $62.4 \pm 11.4$ & $65.6 \pm 18.7$ & NS \\
\hline FEV $1 \%$ pred & $39.8 \pm 13.6$ & $49.4 \pm 11.7$ & $<0.05$ & $34.7 \pm 15.9$ & $40.5 \pm 18.9$ & NS \\
\hline$V \mathrm{~T} \mathrm{~L}$ & $0.71 \pm 0.3$ & $0.84 \pm 0.4$ & $<0.05$ & $0.80 \pm 0.1$ & $0.90 \pm 0.4$ & NS \\
\hline FRC $\%$ pred & $142.7 \pm 54.7$ & $138.3 \pm 32.3$ & NS & $147.6 \pm 48.0$ & $140.4 \pm 52.9$ & NS \\
\hline
\end{tabular}

Values are shown as mean \pm SD. NS: not significant. FVC: forced vital capacity. *: arterial blood gas values were obtained while patients were breathing room air. The p-values are from Wilcoxon signed-rank test. For further abbreviations, see legend to table 1. 
Table 5. - Last available arterial blood gas values and causes of exclusion in patients lost to follow-up

\begin{tabular}{|c|c|c|c|c|c|}
\hline $\begin{array}{l}\text { Patient } \\
\text { No. }\end{array}$ & Causes & $\begin{array}{c}\text { Early } \\
\text { outcomes }\end{array}$ & $\begin{array}{l}{\mathrm{Pa}, \mathrm{O}_{2}} \\
\mathrm{mmHg}\end{array}$ & $\begin{array}{l}{\mathrm{Pa}, \mathrm{CO}_{2}} \\
\mathrm{mmHg}\end{array}$ & $\mathrm{pH}$ \\
\hline $10 \mathrm{~A}$ & Coma & ET intubation & 57 & 69 & 7.21 \\
\hline 16B & Obtundation & ET intubation & 51 & 61 & 7.28 \\
\hline $17 \mathrm{~B}$ & Coma & Death & 41 & 78 & 7.30 \\
\hline 24B & Coma & ET intubation & 54 & 80 & 7.32 \\
\hline
\end{tabular}

Arterial blood gas values were obtained while patients were breathing air with oxygen supplementation. $P \mathrm{a}, \mathrm{O}_{2}$ : oxygen tension in arterial blood; $\mathrm{Pa}_{\mathrm{a}} \mathrm{CO}_{2}$ : carbon dioxide tension in arterial blood: A: group A; ET: endotracheal; B: group B.

are not definitely understood; even more difficult to explain is the fact that such an improvement occurs in patients with ARF of mild severity. From the current data, it may be speculated that nasal ventilation may have reduced the risk for pulmonary infections and the length of hospitalization (that, in turn, might increase risk of infections); moreover, a greater and earlier improvement in pulmonary function may also have contributed. Indeed, only patients treated with nasal ventilation had a significant improvement of arterial $\mathrm{pH}, \mathrm{FEV} 1 \%$ and $V \mathrm{~T}$; in particular, the increase in $V \mathrm{~T}$ in patients typically breathing at low pulmonary volumes and high respiratory rates possibly led to the enhancement of lung mechanics and reduction of muscular fatigue.

At variance with other authors $[4,8,12,20]$, the current authors did not find a significant improvement in early mortality, need for ET intubation, and length of hospitalization in patients treated with NIPPV; however, a clear trend in favour of patients who received NIPPV in addition to medical therapy was clear from the data for each of the above parameters. Differences with studies published earlier may be due to a more severe degree of ARF (more

Table 6. - Cause, time and place of death after hospital discharge during $1 \mathrm{yr}$ follow-up

\begin{tabular}{|c|c|c|c|}
\hline $\begin{array}{l}\text { Patient } \\
\text { No. }\end{array}$ & Cause of death & $\begin{array}{l}\text { Time of death } \\
\text { after discharge } \\
\text { days }\end{array}$ & $\begin{array}{l}\text { Place of } \\
\text { death }\end{array}$ \\
\hline $3 \mathrm{~A}$ & $\begin{array}{l}\text { Exacerbation of COPD; } \\
\text { severe ischaemic heart } \\
\text { disease. }\end{array}$ & 260 & hospital \\
\hline $4 \mathrm{~A}$ & $\begin{array}{l}\text { Cardiac failure in COPD; } \\
\text { severe ischaemic heart } \\
\text { disease. }\end{array}$ & 134 & hospital \\
\hline 18B & $\begin{array}{l}\text { Exacerbation of COPD; } \\
\text { severe ischaemic heart } \\
\text { disease. }\end{array}$ & 45 & hospital \\
\hline 19B & Exacerbation of COPD. & 180 & hospital \\
\hline $25 \mathrm{~B}$ & Exacerbation of COPD. & 78 & hospital \\
\hline 27B & $\begin{array}{l}\text { Exacerbation of COPD; } \\
\text { interstitial lung disease. }\end{array}$ & 60 & hospital \\
\hline 28B & Exacerbation of COPD. & 229 & home \\
\hline 29B & $\begin{array}{l}\text { Exacerbation of COPD; } \\
\text { cardiac failure. }\end{array}$ & 214 & home \\
\hline 30B & $\begin{array}{l}\text { Exacerbation of COPD; } \\
\text { severe silicosis. }\end{array}$ & 146 & hospital \\
\hline
\end{tabular}

A: group A; COPD: chronic obstructive pulmonary disease; B: group B. severe patients may improve remarkedly more) examined in other studies $[4,12]$, or to a shorter period of observational follow-up (in the authors' experience a further worsening may occur after an initial improvement) $[4,20]$ or, finally, to the relatively small sample size of most studies, the present one included.

Although this study gives a further reason to use NIPPV in patients hospitalized because of ARF due to COPD exacerbation, several points on the use of this technique remain controversial. Which patients may benefit, when ventilation should be started and where, what instrument and what treatment schedule should be used, and how timeconsuming for health professionals ventilation is, are, in the authors' opinion the most relevant.

The results demonstrate that patients with exacerbation of COPD and mild or moderate acidosis may benefit, on average, from NIPPV. As stated earlier, this is relevant because the vast majority of patients present with these characteristics in a medical or pneumological setting. Nevertheless, such a conclusion should be considered in the light of the two following observations: the short observational follow-up period of $1 \mathrm{yr}$ and the rather high mortality at 1 yr which also occurred in patients ventilated noninvasively. Therefore, the results need to be confirmed in a larger population over a longer period of time.

In the authors' opinion, it is essential that NIPPV is started quickly and that conventional mechanical ventilation (MV) by ET intubation is available promptly. This was the case in their Division, which, though not equipped with an intensive respiratory care unit, could promptly send intubated patients to the nearby general ICU. Other authors' experience is similar, since they have previously demonstrated the feasibility of NIPPV in a regular medical ward [6] or in a pneumological unit [8]. The current study, as well as that of CONFALONIERI et al. [8], made use of an instrument delivering PSV with an added PEEP; such a way of administering NIPPV seems, at the moment, the most reliable and the most simple, improves respiratory pattern and blood gas values, unloads ventilatory muscles, reduces the effort of breathing, and improves diaphragmatic function in patients with severe stable COPD [21]. Moreover, it is feasible in most patients, since sideeffects are mild and temporary.

The best treatment schedule has not been definitely and objectively defined in the literature. This study followed a practical approach, by ventilating patients for $\sim 20 \mathrm{~h}$ the first day and by reducing the duration of ventilation in the following days. This method, also utilized by others [8], allows the achievement of good results without, generally, over loading patients' respiratory muscles; moreover, it allows patients to take care of their person, take meals, and speak with relatives.

Chevrolet et al. [22] found NIPPV to be a time-consuming procedure for personnel of a general ward, but others did not [23]. The current study cannot give evidece to either position, since it only had two nurses experienced in managing ventilatory technique; however, it is the authors' opinion that only the initial critical phase (1 or 2 days) of NIPPV may require more nursing time in the setting of a regular ward of a division of respiratory diseases.

In conclusion, the results suggest that pressure support ventilation plus positive end-expiratory pressure ventilation delivered through a nasal mask leads to an increased 
Table 7. - Incidence rates of hospital new admissions

\begin{tabular}{lcc}
\hline & $\begin{array}{c}\text { Group } \\
\text { A }\end{array}$ & $\begin{array}{c}\text { Group } \\
\text { B }\end{array}$ \\
\hline Hospital new admissions n & 4 & 6 \\
Cumulative survival person-days & 4774 & 2777 \\
Incidence rate of unfavourable events* \% & 0.084 & 0.216 \\
\hline
\end{tabular}

*: exact test for the difference between the incidence rates was not significant ( $>0.05$ by Binomial probabilities).

survival rate and a reduced incidence of new hospital admissions during the year following discharge in patients with acute respiratory failure of mild and moderate degree due to chronic obstructive pulmonary disease exacerbation. Therefore, it may be added in such patients to conventional medical therapy.

\section{References}

1. Schmidt GA, Hall JB. Acute on chronic respiratory failure. Assessment and management of patients with COPD in the emergency setting. JAMA 1989; 261: 34443453.

2. Vitacca M, Clini E, Porta R, Foglio K, Ambrosino N. Acute exacerbations in patients with COPD: predictors of need for mechanical ventilation. Eur Respir $J$ 1996; 9: 1487-1493.

3. Anthonisen NR. Prognosis in chronic obstructive pulmonary disease: results from multicenter clinical trials. Am Rev Respir Dis 1989; 140: S95-S99.

4. Brochard L, Mancebo J, Wysocki M, et al. Noninvasive ventilation for acute exacerbations of chronic obstructive pulmonary disease. $N$ Engl J Med 1995; 333: 817-822.

5. Meyer T, Hill N. Noninvasive positive pressure ventilation to treat respiratory failure. Ann Intern Med 1994; 120: 760-770.

6. Barbé F, Togores B, Rubi M, Pons S, Maimò A, Agusti AGN. Noninvasive ventilatory support does not facilitate recovery from acute respiratory failure in chronic obstructive pulmonary disease. Eur Respir J 1996; 9: 12401246.

7. Foglio C, Vitacca M, Quadri A, Scalvini S, Marangoni S, Ambrosino N. Acute exacerbations in severe COLD patients. Treatment using positive pressure ventilation by nasal mask. Chest 1992; 101: 1533-1538.

8. Confalonieri M, Parigi P, Scartabellati A, et al. Noninvasive mechanical ventilation improves the immediate and long-term outcome of COPD patients with acute respiratory failure. Eur Respir $J$ 1996; 9: 422-430.

9. Connors A, Dawson N, Thomas C, et al. Outcomes following acute exacerbation of severe chronic obstructive lung disease. Am J Respir Crit Care Med 1996; 154 959-967.
10. American Thoracic Society. Standards for the diagnosis and care of patients with chronic obstructive pulmonary disease (COPD). Am J Respir Crit Care Med 1995; 152: S77-S120.

11. Meduri GU, Abou-Shala N, Fox RC, Jones CB, Leeper KV, Wunderkink RG. Noninvasive face mask mechanical ventilation in patients with acute hypercapnic respiratory failure. Chest 1991; 100: 445-454.

12. Kramer N, Meyer TJ, Meharg J, Cece RD, Hill NS. Randomized, prospective trial of noninvasive positive pressure ventilation in acute respiratory failure. $\mathrm{Am} \mathrm{J}$ Respir Crit Care Med 1995; 151: 1799-1806.

13. Teasdale G, Jennett B. Assessment of coma and impaired consciousness. A practical scale. Lancet 1974; 2: 81-84.

14. Medical Research Council, Commitee on research into Chronic Bronchitis. Standardized questionnaire on respiratory symptoms. BMJ 1960; 2: 1665.

15. Kaplan G, Meier P. Nonparametric estimation from incomplete observations. J Am Stat Assoc 1958; 53: 457481.

16. Peto R, Pike MC, Armitage P, et al. Design and analysis of randomized clinical trials requiring prolonged observations in each patient: analysis and examples. Br J Cancer 1977; 35: 1-39.

17. Corrado A, Bruscoli G, Messori A, et al. Iron lung treatment of subjects with COPD in acute respiratory failure: evaluation of short and long-term prognosis. Chest 1992; 101: 692-696.

18. Corrado A, DePaola E, Messori A, Bruscoli G, Nutini S. The effect of intermittent negative pressure ventilation and long-term oxygen therapy for patients with COPD: a 4 year study. Chest 1994; 105: 95-99.

19. Vitacca M, Clini E, Rubini F, Nava S, Foglio K, Ambrosino N. Non-invasive mechanical ventilation in severe chronic obstructive lung disease and acute respiratory failure: short and long-term prognosis. Intensive Care Med 1996; 22: 94-100.

20. Bott J, Carroll MP, Conway JH, et al. Randomized controlled trial of nasal ventilation in acute ventilatory failure due to chronic obstructive airways disease. Lancet 1993; 341: 1555-1557.

21. Nava S, Ambrosino N, Rubini F, et al. Effect of nasal pressure support ventilation and external PEEP on diaphragmatic activity in patients with severe stable COPD. Chest 1993; 103: 143-150.

22. Chevrolet J, Jolliet P, Abajo B, Toussi A, Louis M. Nasal positive pressure ventilation in patients with acute respiratory failure: difficult and time consuming procedure for nurses. Chest 1991; 100: 775-782.

23. Nava S, Evangelisti I, Rampulla C, Compagnoni ML, Fracchia C, Rubini F. Human and financial costs of noninvasive mechanical ventilation in patients affected by COPD and acute respiratory failure. Chest 1997; 111: 1631-1638. 